\title{
La casa como espacio de resistencias: Comunidades de cuidado para una política feminista antirracistas
}

\section{The house as a space of resistance: Communities of care for a anti-racist feminist politics}

\section{A casa como espaço de resistência: Comunidades de cuidado para uma política feminista antirracista}

\author{
Karina Bidaseca ${ }^{1}$ https://orcid.org/0000-0001-7954-2854
}

\footnotetext{
${ }^{1}$ Profa Pósdoctora - Universidad de Buenos Aires UBA/ Buenos Aires - Argentina, Investigadora de CONICET en NUSUR (Núcleo sur sur de estudios poscoloniales, performances, identidades afrodiaspóricas y feminismos, IDAES/UNSAM. Coordina el Programa Sur-Sur CLACSO y es integrante del GT Afrodescendencias y propuestas contra-hegemonicas de CLACSO. karinabidaseca@yahoo.com.ar
}

Recibido: 20/08/2020

Aceptado para publicación: 28/09/2020

\section{Resumen}

En el contexto de la pandemia, la casa se transformó en el mundo. Frente a la creciente apartheidización, la injusticia colonialista y racial persistentes, la política feminista antirracista que ancestralmente batalla desde la casa, es fuente de inspiración para las resistencias actuales. Las historias afrotransatlánticas brillan en la "poética del mar". Como metáforas, la idea del laberinto caribeño frente al Mediterráneo puede desactivar los artilugios neocoloniales. La pregunta sobre qué experiencias ocurren en el cuerpo colectivo afectado de nuestro tiempo poscolonial de la pandemia abre nuevas reflexiones, citando la escritura performática de la poeta afroamericana Audre Lorde: "Las herramientas del maestro nunca desmantelarán la casa del amo", ¿cómo construir un poder global de hermandades minoritarias que puedan derribar la casa del amo?

Palabras-clave: Covid 19. Feminismo descoloniales. Política antirracista.

\footnotetext{
Abstract

In the context of a pandemic, the house is transformed into the world. In the face of growing apartheidism, colonialist and racial injustices that persist, the feminist anti-racist politics that ancestrally fought from home is the source of inspiration for the current resistance. Afrotransatlantic stories shine in the "poetics of the sea." As metaphors, the idea of the Caribbean labyrinth facing the Mediterranean could deactivate neocolonial artillery. The question about what experiences occurred in the collective body affected by our post-colonial era of the pandemic opens new reflections citing the stage writing of Audre Lorde: "The tools of the teacher will never dismantle the house of love", how to build a group power of minority sororities that could tear down the house of love?
} 
BIDASECA, $\mathrm{K}$.

Keywords: Covid-19. Decolonial feminisms; Anti-racist politics

\section{Resumo}

No contexto de uma pandemia, a casa se transforma no mundo. Diante do crescente apartheidismo, das injustiças colonialistas e raciais que persistem, a política feminista anti-racista que ancestralmente lutou em casa é a fonte de inspiração para a resistência atual. As histórias afrotransatlânticas brilham na "poética do mar". Como metáfora, a ideia do labirinto caribenho voltado para o Mediterrâneo poderia desativar a artilharia neocolonial. A indagação sobre quais experiências ocorreram no corpo coletivo afetado por nossa era póscolonial da pandemia abre novas reflexões citando a redação teatral do poeta afro-americano Audre Lorde: "As ferramentas do professor jamais desmantelarão a casa do amor", como construir um poder de grupo de irmandades minoritárias que poderiam destruir a casa do amor?

Palavras chave: Covid-19. Feminismos descoloniais. Política antirracista.

A Toni Morrison

"Sin comunidad no hay liberación, no hay futuro, sólo el armisticio más vulnerable y temporario entre yo y mi opresión."

Audre Lorde(1979)

\section{Introducción}

En el contexto de la pandemia, la casa se transformó en el mundo. Frente a la creciente apartheidización, la injusticia colonialista y racial persistentes, la política feminista antirracista que ancestralmente batalla desde la casa, es fuente de inspiración para las resistencias actuales. Las historias afrotransatlánticas brillan en la "poética del mar". Como metáforas, la idea del laberinto caribeño frente al Mediterráneo puede desactivar los artilugios neocoloniales. La pregunta sobre qué experiencias ocurren en el cuerpo colectivo afectado de nuestro tiempo poscolonial de la pandemia abre nuevas reflexiones, citando la escritura performática de la poeta afroamericana Audre Lorde: "Las herramientas del maestro nunca desmantelarán la casa del amo".

\section{La casa}


Toni Morrison es una de las escritoras que más ha escrito acerca de la casa y la justicia racial. La casa del 124 en Bluestone Road retratada en Beloved, su obra emblemática, en el sur esclavista de los Estados Unidos en 1873, conserva: "los pensamientos de las mujeres del 124, pensamientos indecibles, no dichos", escribió. Beloved, la niña asesinada por su madre esclavizada y Sethe, víctima de la muerte social, rodean el unheimlich (Freud), el extrañamiento, donde se halla el límite los fundamentos de nuestro juicio ético sobre la esclavitud. Sin embargo, cuando advertimos que en el período que abarca los años 1882 a 1895, entre un tercio y la mitad de la tasa media de mortalidad negra correspondía a niños menores de cinco años (Bhabha, 2002, p. 28), nos enfrentamos al dilema de juzgar el acto acometido.

Sethe, la madre esclava que en un acto de amor decide matar a su hija Beloved, para sustraerla de la apropiación de su amo, era una paria en la sociedad postesclavista de los EEUU. La casa agrisada de Bluestone Road 124 tenía un maleficio: "todo el veneno de un bebé" (p.11). Sethe sufre la muerte social. Nadie visita la casa maldecida del 124. Sethe supo lo que significa para una mujer que alejen a sus hijos cuando sus pechos están llenos de leche; que la golpeen hasta el hartazgo para quitarle $s u$ leche. Fue violada por su amo, como también lo era por los otros esclavos de Sweet Home; un eufemismo infeliz para el nombre de la plantación que se sostenía bajo un sistema de leyes esclavistas que colaboraron en ese trágico destino. Si una esclava se fuga es doblemente castigada; tras ella se pierde la capacidad reproductiva de fuerza de trabajo esclavo. La sociedad esclavista que debe permanentemente producir nuevos esclavos para su reproducción, se ve amenazada. (Bidaseca, 2010, p. 5)

Insistentemente repite: "No era una historia para transmitir. La olvidaron como una pesadilla”,2. ¿Qué es aquello que debe olvidarse prontamente antes de ser transmitido; qué debe permanecer oculto, silenciado para no interrumpir y molestar angustiosamente el fluir de nuestro presente?, me pregunté en 1996 cuando leí su libro por primera vez. "Esta no es una historia para transmitir"; lo hace, dice Homi Bhabha, para que quede grabado en nuestro inconsciente. La historia que narra Morrison, "aunque reclama, no es reclamada"

\footnotetext{
2 Toni Morrison nació en Lorain, Ohio, en 1931. Sus novelas tematizan la cuestión negra en los Estados Unidos, especialmente de las mujeres. Publicó "Beloved" en 1987, con la cual obtuvo el Premio Pullitzer en 1988 y en 1993, el Premio Nobel de Literatura. Otras novelas conocidas son: "Ojos azules" (1970), Sula" (1973), "La canción de Salomón" (1978), "La isla de los caballeros" (1981), “Amor" (2004) y "Una bendición". Su libro "la fuente de la autoestima" fue el último publicado por Ed. Lumen. Falleció el 5 de agosto de 2019.
} 
Morrison reflexionó sobre la casa y la raza de este modo: “...prefiero pensar en un mundo en el que la raza, en efecto, no sea importante. No pienso en un parque temático, ni en un sueño fallido y que siempre falla, ni en la casa paterna con sus muchas habitaciones. Lo concibo como un hogar. Por tres motivos. En primer lugar, porque establecer una distinción radical entre la metáfora de la casa y la del hogar me ayuda a aclarar lo que pienso sobre la construcción racial. En segundo lugar, porque me permite tomar el concepto de la insignificancia de la raza y apartarlo del anhelo y el deseo, apartarlo de un futuro imposible o de un pasado irrecuperable y probablemente inexistente, para acercarlo a una actividad humana manejable y factible. En tercer lugar, porque la labor que puedo hacer es eliminar la fuerza de las construcciones raciales en el lenguaje. No puedo esperar a que llegue la gran teoría de la liberación, defina su funcionamiento y haga su trabajo. Asimismo, tanto las cuestiones relativas a la raza como las relativas al hogar son prioritarias en mi obra y han propiciado, de una u otra forma, mi búsqueda de la soberanía, así como mi abandono de esa búsqueda apenas he reconocido su disfraz."3

Homeplace es aquel lugar que, en su Yearning. Race, gender and cultural politics (1990) bell hooks ${ }^{4}$ concibe como un sitio de resistencia y lucha por la liberación contra el racismo blanco:

Desde que el sexismo delegó a las mujeres la tarea de crear y cuidar un hogar, fue la responsabilidad primaria de las mujeres negras de construir hogares domésticos como espacios de cuidado contra la brutal opresión racista y la dominación sexista. Históricamente, las personas afroamericanas dieron a la construcción del homeplace una dimensión política radical. Citando un monje budista - Thich Nat Hahn- que durante la guerra en Vietnam definió la resistencia como "oposición a ser invadido, ocupado, asaltado y destruido por el sistema (hooks, 1990, p. 43).

En el contexto de la pandemia, la casa se transformó en el mundo. Frente a la creciente apartheidización, la injusticia colonialista y racial que persisten, la política feminista antirracista que ancestralmente batalla desde la casa, es la fuente de inspiración para las resistencias actuales.

\footnotetext{
3 (Conferencia en la Universidad de Princeton, 1994)

${ }^{4}$ Su nombre, con minúsculas, es seudónimo de Gloria Watkins. Fue tomado del nombre de su bisabuela, como una forma de dar voz a las mujeres negras silenciadas.
} 
Las historias afrotransatlánticas brillan en la "poética del mar". Como metáforas, la idea del laberinto caribeño frente al Mediterráneo puede desactivar los artilugios neocoloniales. La pregunta sobre qué experiencias ocurren en el cuerpo colectivo afectado de nuestro tiempo poscolonial de la pandemia abre nuevas reflexiones citando la escritura performática de la poeta afroamericana Audre Lorde: "Las herramientas del maestro nunca desmantelarán la casa del amo”, ¿cómo construir un poder global de hermandades minoritarias que puedan derribar la casa del amo?

\section{El Grito}

La modelización de la estructuración del racismo entre la población afro, habla de la memoria de sus antepasados, transmitida oralmente, silenciando el pasado de africanos esclavos, posiblemente para anular las marcas de la marginación, o bien como estrategia de inserción en una sociedad blanca que invisibilizando esta población, o construyendo guetos para alojarlos, demuestra su fuerte composición de violencia racial.

La negritud femenina en América Latina connota otros rasgos que se fundan en el mito de origen. Así como Carole Pateman (1995) discute la tesis lacaniana de la ley del padre en la fundación del orden social y apela a la violación de la mujer, según Suelí Carneiro:

En Brasil y en América Latina la violación colonial perpetrada por los señores blancos a mujeres negras e indígenas y la mezcla resultante está en el origen de todas las construcciones sobre nuestra identidad nacional, estructurando el decantado mito de la democracia racial latino-americana que en el Brasil llegó hasta sus últimas consecuencias. Esa violencia sexual colonial es también el cimiento de todas las jerarquías de género y raza presentes en nuestras sociedades configurando aquello que Ángela Gilliam define como la gran teoría del esperma en la formación nacional a través de la cual, y siguiendo a Gilliam, el papel de la mujer negra es rechazado en la formación de la cultura nacional; 2. la desigualdad entre hombre y mujer es erotizada; y 3. la violencia sexual contra las mujeres negras ha sido convertida en un romance (Carneiro, 2002, p. 4).

Desde este lugar se torna de especial importancia pensar las violencias, particularmente, las de las luchas de las mujeres negras frente a la cosificación sexual perpetuada por la violencia de la mirada cosoficante del varón blanco. Como un ser hipererotizado, cuya función primaria es satisfacer el deseo sexual y la reproducción,los cuerpos femeninos negros resisten la cosificación. La hipersexualización de los cuerpos 
negros de las mujeres es objeto de tratamiento constante en el pensamiento del feminismo negro.

En los últimos años la estatua del doctor James Marion Sims había sido bajada de su pedestal en Central Park en Nueva York. "Conocido en los Estados Unidos como el padre de la ginecología moderna, nacido en Carolina del Sur, Sims estudió medicina y la practicó en una sociedad todavía esclavista en Alabama entre 1835 y 1849. Allí, según consta en sus cuadernos, llevó a cabo operaciones a una decena de esclavas. Posteriormente se desplazó a Nueva York, donde fundó el primer hospital para mujeres en 1855. Fue pionero en la intervención de fístula y también inventó el espéculo y otros instrumentos médicos que se utilizan actualmente. Los activistas han denunciado durante años que sus logros se basaron en experimentos con esclavas afroamericanas",

El estado de Nueva York, comenzó a negociar la abolición de la esclavitud en 1799 y emancipó a todos los esclavos el 4 de julio de 1827. No obstante, amos como John Dumont renunciaron a emancipar a las esclavizadas. Sojourner Truth, conocida por el célebre discurso "Acaso no soy una mujer", a finales de 1826 se fugó hacia la libertad con su hija menor, Sophia. Su otra hija y su hijo se quedaron atrás. Truth se enteró de que su hijo Peter, de 5 años de edad, había sido vendido ilegalmente a un hombre de Alabama. Llevó el asunto ante los tribunales y consiguió el regreso de Peter. Es uno de los primeros en que una mujer negra desafió con éxito a un hombre blanco en un tribunal de los Estados Unidos. El 1 de junio de 1843, Isabel Baumfree cambió su nombre por Sojourner Truth, dedicando su vida al metodismo ya la abolición de la esclavitud. ${ }^{6}$

En 1850 sus memorias fueron publicadas bajo el título "La narrativa de la verdad de Sojourner Truth: Una esclava del norte.” Dictó sus recuerdos a un amigo, Olive Gilbert, ya que no sabía leer ni escribir. Ese mismo año, Truth habló en la primera Convención Nacional de Derechos de la Mujer en Worcester, Massachusetts. Empezó a viajar con el abolicionista George Thompson, y le habló a multitudes sobre esclavitud y derechos humanos ${ }^{7}$.

Luego de manifestaciones multitudinarias en las ciudades por el asesinato de George Floyd el 25 de mayo de 2020 en la ciudad de Minnesotta, monumentos de esclavistas y racistas fueron derribados: en Indianápolis, Indiana; Rocky Mountain, Carolina del Norte; en

\footnotetext{
${ }^{5}$ Tomado de: https://elpais.com/internacional/2018/04/18/mundo_global/1524036400_696258.html.

${ }^{6}$ En 1844, se unió a la Asociación de Northampton de Educación e Industria en Northampton, Massachusetts. Fundada por abolicionistas, la organización apoyó una amplia agenda de reformas incluyendo los derechos de las mujeres y el pacifismo. Conoció allí a los abolicionistas Guillermo Lloyd Guarnición, Frederick Douglass y David Ruggles.

${ }^{7}$ Texto tomado de (https://www.biography.com/people/sojourner-truth-9511284)
} 
Roanoke y Norfolk, Virginia, en proceso de remoción. En Richmond se derribó la estatua de Jefferson Davis, presidente de la Confederación. "Jefferson Davis era un racista y traidor que huyó de nuestra ciudad mientras sus tropas llevaban órdenes de quemarla", dijo el alcalde, Levar Stoney. ${ }^{8}$

\section{Améfrica}

El radicalismo de las Mujeres de color y la "Amefricanidad" en el pensamiento de la filósofa feminista Lélia González, quien mostró la silenciada construcción de la mujer negra en la historia oficial de Brasil tiene una decisiva influencia en América Latina. En este proceso la intersección de los sistemas de opresión social, el sexismo, racismo han contribuido a esa desaparición.

En la colonia la historia fue escrita por los colonizadores europeos, todos ellos en su gran mayoría hombres blancos letrados. Sin embargo, hubo esclavizadas y esclavizados que dominaron la escritura y dejaron relatos importantísimos. Tal es el caso de Rosa María Egipcíaca da Vera Cruz, una mujer ex esclavizada que escribió un libro sobre su visión en el siglo XVIII. O de Esperanza García quien escribió una carta al gobernador de Piauí en 1770 para reclamar por malos tratos del administrador de hacienda real en la que trabajaba. $\mathrm{O}$ de otra mujer negra, María Firmina dos Reis que fue la primera mujer en publicar un libro en Brasil en 1859 (citado en Cartilla Somos todas rainhas, 2012). ${ }^{9}$

Lélia González había sido profesora universitaria y sus estudiantes, entre las y los que se cuentan Viana, la recuerdan como una gran pensadora y activista que dejó un legado muy importante para el feminismo negro, que era incipiente en Brasil. González había escrito, junto con el autor argentino radicado en Brasil, Carlos Hasenbalg, un libro titulado Lugar de negro (1982). En una sociedad periférica del sistema capitalista, edificada sobre la democracia racial sustentado por Gilberto Freyre, el lugar del negro era componer la gran masa marginal creciente. Para las mujeres negras —as màes pretas, las empleadas domésticas y las mulatas_- ese lugar era, sin dudas, sostienen los autores, mucho más frágil.

\footnotetext{
${ }^{8}$ Tomado de https://www.cnn.com/2020/06/09/us/confederate-statues-removed-george-floyd-trnd/index.html

9 Este es el trabajo de rescate de esas voces femeninas silenciadas que están llevando adelante grandes mujeres en torno de la Colección Historia das Mulheres Negras: Pasado, Presente e Futuro y cuya autora Giselle Cristina dos Anjos Santos me obsequió recientemente en gran el encuentro de mujeres de Brasil Fazêndo Genero con participación de activistas, artistas e intelectuales de la región.
} 
El pensamiento de Lélia González era radical. Estaba atravesado por el debate sobre la misceginación y la violencia sexual de la esclavitud, recuperado por la feminista Suelí Carneiro. No dudó en criticar a la izquierda brasilera de los setentas, por reproducir la injusticia racial; al feminismo por no reconocer esa opresión, y al movimiento negro por reproducir la opresión sexual. Para contestar al cientificismo académico, se valió del psicoanálisis y de intelectuales negros como Fanon. Las marcas del legado fanoniano en el feminismo negro de Brasil nos permiten interpretar la categoría de amefricanidad ${ }^{10}$ de Lélia Gonzalez.

Lélia de Almeida, nacida el 1 de febrero de 1935 en Belo Horizonte, penúltima y décimo séptima hija de padre negro y madre india, con oficios de ferroviario y de empleada doméstica. Su biografía narra la capacidad de la joven que logra atravesar la barrera de color, ingresando en la universidad y convirtiéndose más tarde en profesora universitaria. Un hecho importante que permite comprender esta movilidad ascendente es el trabajo que su madre realiza para una familia italiana, como ama de leche de una niña cuya madre falleciera en el parto. Lélia tenía la misma edad que la niña huérfana y las unía lazos afectivos y en la edad escolar la familia ofreció pagar los estudios de Lélia. «Estudié con mucha dificultad. Los libros eran prestados por las colegas hasta llegar a la Universidad» (citado por Viana, 2006, p. $48)^{11}$.

Resulta importante destacar en el relato que destaca lo que percibió la jovenal haber atravesado el sistema educativo brasilero: «al llegar a la universidad ya estaba emblanquecida», escribió. Destaca como esa ideología del emblanquecimiento opera en el individuo. Es ese el momento en que, según Viana, busca el «acogimiento espiritual en el candomblé a pesar del respeto a sus raíces culturales católicas, y su posición favorable a la teología de la liberación. Es en esa práctica religiosa anteriormente tenida por ella como primitiva que encuentra otro código cultural, mas próxima de su religiosidad porque está «mas africanizada que occidentalizada» (Viana, 2006, p. 3).

Este momento puede leerse como el paso a la concientización sobre qué significa ser mujer negra en Brasil y en América. En ese camino Lélia González trabajará por desmitificar la consabida democracia racial, en el contexto de un fuerte compromiso político que provoca su expulsión de Facultad de Filosofía de Campo Grande y Filosofía, Ciencias y Letras, y su convite a la Pontificia Universidad Católica de Río de Janeiro en el período de

\footnotetext{
10 «A categoría político cultural da amefricanidade». Revista Tempo brasilero, Rio Janeiro, 1988 p. 73.

${ }^{11}$ Véase Elizabeth Di Espirito Santo Viana, «Relaçoes raciais, gênero e movimentos sociais: O pensamiento de Lélia Gonzalez (1970-1990)». Tesis de Maestría, UFRJ, Brasil.
} 
recrudecimiento del régimen militar, cuando fue sospechada por los órganos de seguridad de buscar adeptos a la doctrina marxista.

La joven universitaria se impacta con la efervescencia de la comunidad negra joven en el contexto de las luchas por los derechos civiles en Estados Unidos ${ }^{12}$, y las guerras de liberación de pueblos africanos negros de lengua portuguesa, cuyas voces tendrán un lugar en el libro. Entre ellos la figura de Abdías do Nascimento, líder del Teatro Experimental del Negro, y el desempeño de las jóvenes valientes mujeres negras en la formación del Movimiento Negro, marcando su posición, denunciando que en «esa herencia cruel de la esclavitud en el continente americano el destino de la mujer negra era ser objeto de producción y reproducción sexual» (Viana, 2006, p. 64).

Para la pensadora brasilera fueron las mujeres negras cariocas las precursoras del movimiento autónomo de las mujeres en el feminismo negro. Próximos a celebrarse el Año Internacional de la Mujer en 1975, en el seno del movimiento negro se desarrollan escritos sobre la actuación política de las mujeres. El testimonio de Joana Angélica, citado por Viana, menciona el trabajo realizado sobre el libro de Fanon Piel negras... en un momento en que «estábamos tirando las máscaras blancas» (Viana, 2011, p. 64). Estas jóvenes escribieron un documento en el que denunciaban la herencia cruel de la esclavitud en el continente americano, el destino de la mujer negra como objeto de producción y reproducción sexual. Para ellas el fruto de esa «cobarde procreación de los colonizadores es que, aclamado como un único producto nacional que puede ser exportado: la mujer mulata brasilera. Pero si la calidad de este producto es considerada como alta, el tratamiento que ella recibe es extremadamente degradante e irrespetuoso» (González y Hasenbalg, 1982, p.36).

El debate sobre lo simbólico en el Colegio Freudiano que Lélia González co-fundó en 1975/6 en Río de Janeiro, fue clave para vivenciar sus experiencias religiosas dentro del candomblé, la dimensión de la ancestralidad, con la naturaleza, con los animales, con la energía cósmica Helena Theodoro, (citada por Viana, 2006). Sin dejar de trabajar en el Movimiento Negro Unificado (MNU)la articulación entre raza y clase: «Hoy, decía Lélia, no da más para sustentar posiciones culturalistas, intelectualistas divorciadas de la realidad vivida por las masas negras, colocada por el MNU en esa articulación»(Viana, 2011, p. 80)

Las mujeres dentro del MNU se encontraban con que su militancia política era menospreciada. Nació así REMUNEA — Reunión de Mulheres Negras AQUaLTUNE——

\footnotetext{
${ }^{12}$ El jornal «Quilombo», editado por el Teatro Experimental del Negro, mantendrá correspondencia con la revista Presencia Africana y con figuras internacionales (Viana, 2006: 36).
} 
en el que participaba Lélia González, imprimiendo en sus trayectorias de vida una marca de innegables consecuencias. Como es posible leer en su libro:

También nosotras, mujeres negras, además de la denuncia de blanqueamiento del hombre negro, en términos de casamiento, discutimos los problemas relacionados a la educación de nuestras crianzas, control de natalidad, como nuestra participación en el proceso de liberación del pueblo negro y en la lucha contra el racismo. Analizamos también la situación de la mujer negra en cuanto empleada doméstica en el marco de la reproducción del racismo inclusive por parte de muchas militantes blancas del movimiento de mujeres (Gonzales, citado por Viana, 2006, p. 87).

En 1982 Lélia González escribe una gran contribución tituladaV mulher negra na sociedade brasilera. Uma abordagem político-económica, en que expone su mirada crítica a Gilberto Freyre sobre los casamientos interraciales, que fueron hechos sobre la violencia de mujeres negras por parte de la minoría blanca dominante — señores de los ingenios, traficantes de esclavos, etc.——_Cómo fue que ocurrió que el mito tuvo tanta divulgación? ¿Qué es lo que oculta? ¿Qué lugar ocupa la mujer negra?», se preguntaba, desde su propia vivencia como luchadora feminista negra, por esa articulación de racismo y sexismo.

\section{Poética erótica de la Relación}

La exploración acerca del pensamiento situado y del afrocentrismo en la obra de la artista cubana de color Ana Mendieta nos ubica en su casa de La Habana, en su cuidado por amas negras y su exilio posterior a los 12 años de edad. Las prácticas de éstetesis femeninas transatlánticas, tomando la obra de la artista en Oaxaca, México y en Cuba, para abrazar los conceptos organizadores de "territorios de la memoria", "arte feminista situado y descolonial". Momentos de la obra de la artista entre los años 1977 a 1982 me permiten desarrollar el concepto de "poética (erótica) de la Relación”, acuñado por mí en la inspiración del cruce de obra de Édouard Glissant y Audre Lorde, como propia de la territorialización de la memoria.

Ana Mendieta es exilio, es devenir, es hermandad erótica fraguada en los poemas de la afrofeminista Audre Lorde; es la posibilidad de la transmutación en otros seres; es la posibilidad de reunirnos en las fuerzas de la energía del cosmos, del universo estallado y de crear una "poética erótica de la Relación”, concepto que acuñé en un texto reciente forjado en la síntesis del pensamiento glissantiano y afrofeminista lordeano (BIDASECA, 2018). 
En 1961, Ana Mendieta, de origen cubano, llegó a Dubuque, Iowa, como refugiada, arrancada a la Revolución Cubana por medio de la operación Peter Pan, preparada por la iglesia, que se propuso "salvar" a los niños del comunismo.

Entre sus escritos Ana Mendieta escribe:

He estado conduciendo un diálogo entre el paisaje y el cuerpo femenino - basado en mi propia silueta - Creo que esto ha sido resultado directo de haber sido arrancada de mi tierra natal — Cuba - durante mi adolescencia. Estoy abrumada por el sentimiento de haber sido arrojada del vientre - la naturaleza- Mi arte es la forma que restablezco los lazos que me unen al universo. Es un regreso a la fuente materna. A través de mis esculturas de tierra/cuerpo me hago una sola con la tierra. Me convierto en una extensión de la naturaleza y la naturaleza se convierte en una extensión de mi cuerpo. Este acto obsesivo de afirmar mis lazos con la tierra es en realidad una reactivación de creencias primigenias... en una fuerza femenina omnipresente, la imagen posterior de estar encerrada en el útero; es una manifestación de mi sed de ser. (Mendieta, 1988, p.17).

La tierra habla (Lippard;Mendieta; Mosquera, 2019) documenta obras de tierra específicas de sitio desde su exilio a Estados Unidos al regreso a la Cuba natal, pasando por Oaxaca, expandiendo una propia temporalidad y abrazando distintos mundos:

1. Iowa, Estados Unidos: Serie Siluetas. Desde 1977 la artista realizó imágenes inquietantes de sus más conocidas "Siluetas", para las cuales trazó el contorno de su cuerpo en la tierra y fango, en el mar, en los árboles, utilizando el fuego en obras como: Ànima, Alma soul Ñáñigo brutal (1976); Serie árbol de la vida (Tree of Life Series); Serie Fetiches.

2. Oxaca, México. Salina Cruz, realiza Siluetas y videos, tales como: Ocean Bird y Perro.

3. La Habana, Cuba (1980). Escaleras de Jaruco y Guanabo, desde 1981. Se destacan sus esculturas rupestres que se asemejan a petroglifos que talló en piedra caliza, durante su regreso a Cuba. Mendieta vio las obras como una fusión con el territorio insular y con su ancestralidad indígena taína. Las formas que ella inscribió en las cuevas se refieren a antiguas deidades femeninas y maternas. Son vaginas, son rostros femeninos que deja esas obras en las paredes de La Cueva del Águila, basándose en la técnica que utilizaban los indígenas: La Concha de venus; Maroya Moon/Luna; Bacayú; Madre Vieja ensangrentada y Guacar. Nuestra Menstruación.

4. Roma, Italia (1984 y 1985). Consideraremos esta obra desde una episteme afrocentrista. En tanto, la “colonialidad del poder y de género" (Quijano, 1993; Lugones, 2008) trae aparejada también un modo concreto de producir conocimiento eurocentrado, que funciona produciendo categorías que se presentan como universales y a-históricas, lo cual 
tiene como consecuencia la 'homogeneización' de procesos sociales e históricos (BIDASECA, 2016).

Asimismo, recientemente sus cartas y dibujos que se trazaron durante su estancia en Roma, fueron expuestos por el artista Wilfredo Pietro en la Galería Nogueras Blanchard en Madrid. En el propio título de la muestra: Tropic-Ana firmaba informalmente su correspondencia con familiares y amigos. Es en una de estas misivas donde contaba desde Nápoles: "Querida mamita, nada más unas líneas para darte la buena noticia de que voy a tener una muestra en Roma que inaugura marzo 21 la Galería Primo Piano. En fin, mis labores empiezan a tener fruto". 13

\section{Comunidades de cuidado en tiempos de covid-19: consideraciones finales}

"En mi casa este año estamos celebrando la fiesta de Kwanza, el festival afroamericano de la cosecha que comienza el día después de Navidad y dura siete días. Hay siete principios de Kwanza, uno para cada día. El primer principio es Umoja, que significa unidad, la decisión de trabajar por y mantener la unidad de sí misma y de la comunidad. El principio para ayer, el segundo día, era Kujichagulia: autodeterminación, la decisión de definirnos nosotras mismas, darnos un nombre nosotras mismas, y hablar por nosotras mismas, en lugar de ser definidas y descriptas por otros. Hoy es el tercer día de Kwanza, y el principio para hoy es Ujma: trabajo colectivo y responsabilidad, la decisión de construir y mantenernos unidas nosotros mismos y a nuestras comunidades, y de reconocer y solucionar nuestros problemas juntos", escribe Audre Lorde en "Diarios del Cáncer” en los años de 1980 recordando su casa mientras se encontraba en el hospital batallando contra el cáncer de mama.

Hoy las favelas de Brasil organizan su propia lucha contra el coronavirus. Las mujeres en el barrio Paraisópolis de San Pablo, asisten a un incremento de casos desde el mes de marzo. El desplazamiento del virus a América del Sur entreveía que estos barrios serían devastados. El virus ha afectado desproporcionadamente a las favelas pobres de Brasil, en su mayoría negras. En Sao Paulo, las personas que viven en zonas más pobres y contraen el virus tienen hasta 10 veces más probabilidades de morir que las personas en áreas ricas, según datos publicados por el departamento de salud de la ciudad. Los residentes afrodescendientes de Sao Paulo tienen un 62 por ciento más de probabilidades de morir por el

${ }^{13}$ texto tomado de https://www.hoyesarte.com/evento/la-historia-del-cuerpo-de-tropic-ana/ 
virus que los residentes blancos. Las favelas son una gran casa de activismo y resistencias. Abandonadas por los servicios gubernamentales, la nota publicada por el Diario Washington Post muestra que las comunidades han creado instituciones paralelas -incluidos el correo, Internet y los sistemas de saneamiento- trabajando en los sistemas de salud y de educación. Una de las alternativas que elaboraron las mujeres fue el programa de "Presidentes de la calle" para monitorear y frenar la propagación del virus. "Decidimos crear alternativas para que si el gobierno no hacía su trabajo, pudiéramos movilizarnos para prevenir el sufrimiento en la comunidad", dijo ${ }^{14}$.

En la favela Complexo do Alemáo de Río de Janeiro se creó una propia base de datos para rastrear la enfermedad. La asociación de residentes en la comunidad de Cantagalo de Río se unió a una organización no gubernamental local para rociar desinfectante. "Después de que Juliana Carmo, de 20 años, viera mensajes que se extendían en las redes sociales diciendo a la gente del barrio Honório Gurgel de Río que los climas cálidos frenarían el coronavirus y que las máscaras donadas estaban contaminadas con el virus, se asoció con otros jóvenes de Río para mapear y combatir las fake news (noticias falsas)." Proymás produjeron un video que aborda la desinformación más común y establecieron una línea directa para ayudar a las personas, dicen. ${ }^{15}$

La acción basada en la comunidad es la llave de la puerta de nuestra casa: "Sin comunidad no hay liberación”, expiró Audre Lorde cobijándonos en su casa.

\section{Referencias}

Bidaseca, Karina et al. La articulación entre raza, género y clase a partir de Aníbal Quijano. Diálogos interdisciplinarios y lecturas desde el feminismo. Papeles de trabajo, IDAESUNSAM, 10, (18), 2016.

Bidaseca, K. (2018). La revolución será feminista o no será: la piel del arte feminista descolonial. Buenos Aires: Prometeo,

Bidaseca, K. (2020) "La casa, el mundo. Políticas feministas antirracistas y comunidades de cuidado", en el Boletín $N^{o} 3$ Ancestralidad, antirracismo y actualidad. La pandemia

\footnotetext{
14 tomado de: https://www.washingtonpost.com/world/the_americas/coronavirus-brazil-favela-sao-paulo-rio-janeirobolsonaro/2020/06/09/8b03eee0-aa74-11ea-9063-e69bd6520940_story.html

15 texto tomado de:https://www.washingtonpost.com/world/the_americas/coronavirus-brazil-favela-sao-paulo-rio-janeirobolsonaro/2020/06/09/8b03eee0-aa74-11ea-9063-e69bd6520940_story.html /Traducción Andrew Wilson)
}

Geopauta, Vitória da Conquista, ISSN: 2594-5033, V. 4, n. 3, 2020, p.(45-59) http://periodicos2.uesb.br/index.php/geo, 
racializada. Bs As: CLACSO, julio 2020.file://Users/karinabidaseca/Downloads/ V3_Ancestralidad_antirracismo_actualidades_N3_compressed.pdf/ https://www.clacso.org/boletin-3-ancestralidad-antirracismo-y-actualidades/

Bidaseca, K. (2020) "Territorializar las memorias, abrazar los mundos. Ana Mendieta, arte feminista situado". En Revista CDM. Arquivos CMD - Cultura Memória e Desenvolvimento. Dossiê bilíngue "Gênero, Memória e Cultura" / "Género, Memória y Cultura".

Bhabha, H. Conversation between John Comaroff and Homi Bhabha. In: Goldberg, D; Auayso, A. (Orgs.). Relocating postcolonialism. New York: Blackwell, 2002. p. 17-36.

Campoalegre Septien, R. Y Bidaseca, K. (2017) (Coord.) Más allá del decenio de los pueblos afrodescendientes. (Buenos Aires, CLACSO).

Carneiro, S. [2002]. Ennegrecer el feminismo. Conferencia presentada en Durban, 2002. Disponible en http://www.penelopes.org/Espagnol/xarticle.php3?id_article=24

Gonzalez, L.; Haselbag, C. [1982]. Lugar de negro. Río de Janeiro: Marco Zeero, 1982Fanon Frantz. (1970) ¡Escucha, blanco! Barcelona (Ed. Nova Terra).

Hooks, B. (1990) Yearning. Race, gender and cultural politics. (Boston: South End Press).

Lippard, L.R.; Lovarlt, A.; Mendieta, C.R.; Mosquera, G.(2019) Ana Mendieta: La Tierra Habla (the Earth Speaks). New York, Galerie Lelong

Lorde, A. (1978) Uses of the Erotic: The Erotic as Power. En Sister Outsider. Ten Speed Press.

Lorde, A. [1979] Los diarios del cáncer. - 1a ed. Traducido por: Gabriela Adelstein. Rosario: Hipólita Ediciones, 2008.

Lorde, A. (1988) "La casa del amo no se desarma con las herramientas del amo", en Moraga, Cherríe; Castillo, Ana (ed.) Esta puente mi espalda. Voces de mujeres tercermundistas en los Estados UnidoS (San Francisco: ISM Press).

Lugones, M. (2008) Colonialidad y género, Tabua Rasa, nº 9, Bogotá

Quijano, A. (2003) Colonialidad del poder, eurocentrismo y América Latina. En: Lander (comp.). La Colonialidad del Saber: eurocentrismo y ciencias sociales. Perspectivas latinoamericanas. Buenos Aires: CLACSO,

Santos, G. C. A. (2012) Somos todas rainhas. São Paulo: Associação Frida Kahlo,

Viana, Elizabeth (2006). «Relaçoes raciais, gênero e movimentos sociais: O pensamiento de Lélia González (1970-1990)». Tesis de Maestría, UFRJ, Brasil 
La casa como espacio de resistencias. Comunidades de cuidado para una política feminista antirracistas BIDASECA, $\mathrm{K}$.

Geopauta, Vitória da Conquista, ISSN: 2594-5033, V. 4, n. 3, 2020, p.(45-59) http://periodicos2.uesb.br/index.php/geo, 